\title{
Efeito da suplementação de enzima fitase sobre o metabolismo de nutrientes e o desempenho de poedeiras ${ }^{1}$
}

\author{
Maurício Tárcio dos Santos Viana ${ }^{2}$, Luiz Fernando Teixeira Albino ${ }^{3}$, Horacio Santiago \\ Rostagno ${ }^{3}$, Sergio Luiz de Toledo Barreto ${ }^{3}$, Eliane Aparecida da Silva ${ }^{4}$, Wenderson \\ Magno Florentino ${ }^{5}$
}

\footnotetext{
1 Projeto apoiado pelo CNPq.

${ }^{2}$ Pós-graduação em Zootecnia - Universidade Federal de Viçosa, DZO - UFV, Viçosa, MG. Bolsista CNPq.

${ }^{3}$ Departamento de Zootecnia, UFV - 36571-000 - Viçosa, MG.

${ }^{4}$ Pós-graduação em Zootecnia, UFV - 36571-000 - Viçosa, MG.

${ }^{5}$ Curso de graduação em Zootecnia, UFV - 36571-000 - Viçosa, MG.
}

RESUMO - Avaliou-se o efeito da adição da enzima fitase sobre o desempenho e o metabolismo de poedeiras comerciais. Foram utilizadas 360 poedeiras da linhagem Bovans Goldline, distribuídas em delineamento inteiramente casualizado, com 12 repetições de 6 aves por unidade experimental e 5 tratamentos, que consistiram de cinco dietas: controle positivo; controle negativo (CN) com 0,15\% de fósforo disponível; CN + 200 FTU de fitase; CN + 400 FTU de fitase; CN + 600 FTU de fitase. A dieta controle positivo foi formulada segundo recomendações das Tabelas Brasileiras e a dieta controle negativo com fósforo disponível foi calculada reduzindo os nutrientes presentes na matriz nutricional da enzima, de acordo com recomendação da empresa produtora. Os parâmetros avaliados foram: consumo de ração, produção de ovos, peso dos ovos, massa de ovo (MO), conversão por massa de ovo (CAMO), conversão alimentar por dúzia e componentes do ovo no período de 24 a 36 semanas de idade. No ensaio de metabolismo, calcularam-se os coeficientes de digestibilidade aparente da matéria seca, da energia metabolizável aparente e da energia metabolizável corrigida, bem como seus coeficientes de metabolizabilidade, além da retenção de nitrogênio e do balanço de P e Ca das dietas experimentais. A adição da enzima fitase (200, 400 e 600 FTU) proporcionou produção de matéria orgânica e conversão por massa de ovo semelhante à das poedeiras alimentadas com a ração controle positivo. Os componentes de ovo não foram influenciados pelas rações, com exceção do peso da casca, que aumentou com a suplementação de fitase nas dietas. A adição de 600 FTU de fitase melhora o metabolismo dos nutrientes da dieta em poedeiras comerciais.

Palavras-chave: digestibilidade, energia metabolizável, fósforo, metabolizabilidade, ovos

\section{Effect of dietary supplementation of phytase on laying hens performance and nutrient metabolism}

\begin{abstract}
The effect of the addition of phytase enzyme on performance and metabolism of laying hens was evaluated. Three hundred and sixty Bovans Goldline hens were allotted to a completely randomized design, with 12 replicates of 6 birds per unit and 5 experimental treatments as follows: $\mathrm{T}_{1}=$ positive control $(\mathrm{PC}), \mathrm{T}_{2}=$ Negative control (NC by $0.15 \%$ phosphorus available), $\mathrm{T}_{3}=\mathrm{NC}+200 \mathrm{FTU}$ of phytase, $\mathrm{T}_{4}=\mathrm{NC}+400 \mathrm{FTU}$ of phytase, $\mathrm{T}_{5}=\mathrm{NC}+600 \mathrm{FTU}$ of phytase The positive control diets were formulated to contain adequate nutrient levels according to recommendations of the Brazilian Tables. Diet of treatments 2, 3, 4 and 5 (Negative Control) were calculated with reduced contents of nutrients present in the nutritional contribution of the enzyme complex evaluated according with recommendations from the manufacturer. The parameters evaluated were: feed intake, egg production, egg weight, egg mass and feed:gain ratio (per g of egg mass and per dozen of egg). In the metabolism trial, feed consumption and total excreta production per replicate were measured to determine the metabolizable energy values (apparent ME and apparent nitrogen corrected ME), metabolizability coefficients of gross energy and nitrogen retention and $\mathrm{P}$ and Ca balance of the experimental layer diets. The addition of phytase (200, 400 and $600 \mathrm{FTU})$ to the negative control diet resulted in layers with egg mass production, feed:gain ratio per egg mass similar to layers fed the positive control diet. The egg components parameters were not affected by treatments, except the eggshell weight, which increased with the addition of phytase in the diets. The addition of 600 FTU of phytase improve the metabolism of nutrients in nutritionally deficient diets.
\end{abstract}

Key Words: digestibility, eggs, metabolizability, metabolizable energy, phosphorus 


\section{Introdução}

Nos últimos anos, a nutrição animal passou a utilizar maiores quantidades de ingredientes de origem vegetal em substituição aos de origem animal; no entanto, 2/3 do fósforo presente nesses ingredientes se encontra na forma de ácido fítico.

Segundo Cromwell (1991), a fitase é uma enzima que atua nas ligações do grupo fosfato do fitato, liberando o fósforo e outros minerais que fazem parte dessa molécula. Além de melhorar a disponibilidade do fósforo, o uso dessa enzima também melhora a disponibilidade de outros minerais, como magnésio, manganês, cobre, ferro e zinco.

Animais monogástricos não sintetizam a enzima fitase e têm como conseqüência baixa eficiência no aproveitamento do fósforo de origem vegetal. Como o fósforo é um mineral essencial por desempenhar importantes funções nos processos metabólicos, ao formular dietas para aves, torna-se necessário adicionar uma fonte de fósforo inorgânico.

Os primeiros estudos desenvolvidos com a enzima fitase, apesar de promissores, tiveram como entrave o alto custo no processo de obtenção do produto. Entretanto, com o avanço da tecnologia de fermentação, a fitase vem sendo comercializada industrialmente, o que tem despertado maior interesse de diversos nutricionistas preocupados com o alto custo do fósforo inorgânico e com a poluição ambiental causada pelo excedente de fósforo excretado (Cromwell et al., 1995; Moreira et al., 2000; Moreira et al., 2001).

Sob o ponto de vista da nutrição, a viabilização técnica das enzimas exógenas é um marco importante, pois permite melhor aproveitamento dos nutrientes. $\mathrm{O}$ aumento na utilização do fósforo, dos aminoácidos e da energia por meio da utilização da enzima fitase representaria economia significativa no custo final da formulação das dietas.

Os primeiros estudos sobre ação dessa enzima foram realizados por Nelson et al. (1968), que reconheceram o potencial da fitase ao tratarem farelo de soja com fermentado de Aspergillus ficuum e verificavam melhoria na utilização do fósforo fítico em dietas para aves.

Apesar da extensa literatura e dos dados que confirmam o uso de fitase em frangos de corte, existem poucos estudos avaliando seu uso em poedeiras. Portanto, o objetivo com esta pesquisa foi determinar a eficácia da Quantum ${ }^{T M}$ Fitase em dietas à base de milho e de farelo de soja sobre o desempenho e o metabolismo de poedeiras.

\section{Material e Métodos}

Dois experimentos foram conduzidos no Setor de Avicultura do Departamento de Zootecnia da Universidade Federal de Viçosa no período de 26 de abril a 18 de julho de 2007.

Inicialmente as aves foram selecionadas de acordo com o peso corporal para uniformização do lote e por um período de 4 semanas a produção foi controlada individualmente para posterior redistribuição para equalização da produção.

No experimento 1 , foram utilizadas 360 poedeiras da linhagem Bovans Goldline, de 24 a 36 semanas de idade durante três períodos experimentais de 28 dias. As aves foram alojadas em galpão de alvenaria com cobertura de telhas de barro em duas águas, telado, com pé-direito de 2,0 m e composto internamente por gaiolas de arame galvanizado com quatro compartimentos de $25 \times 45 \times$ $40 \mathrm{~cm}$, distribuídas lateralmente em dois andares, distantes $0,80 \mathrm{~m}$ do piso. O comedouro e bebedouro utilizados foram do tipo calha galvanizada, percorrendo toda extensão frontal das gaiolas.

Durante todo o período experimental, a temperatura no interior do galpão foi monitorada diariamente, duas vezes ao dia (às 8 e às 16 h), por meio de termômetros de máxima e mínima. As aves receberam ração e água à vontade e 17 horas de luz por dia durante todo o período experimental, respeitando as recomendações de manejo do manual da linhagem. Os ovos foram colhidos duas vezes ao dia (8 e 16 h), com anotação, em fichas apropriadas da freqüência de postura e da mortalidade.

O delineamento experimental utilizado foi inteiramente casualizado em 5 tratamentos, cada um com 12 repetições de 6 aves por unidade experimental. Os tratamentos aplicados consistiram de cinco dietas: controle positivo - Tabelas Brasileiras; controle negativo (CN) com 0,15\% de P disponível; CN + 200 FTU Quantum ${ }^{T M}$ Fitase $(80$ g/t); CN + 400 FTU Quantum ${ }^{T M}$ Fitase $(160 \mathrm{~g} / \mathrm{t})$; e CN +600 FTU Quantum $^{T M}$ Fitase (240 g/t).

A dieta controle positivo foi formulada à base de milho e farelo de soja, segundo recomendações das Tabelas Brasileiras (Rostagno et al., 2005). As dietas formuladas a partir da controle negativo foram calculadas reduzindo $45 \mathrm{kcal} / \mathrm{kg}$ de energia metabolizável, 0,36\% de proteína bruta, $0,115 \%$ de Ca, $0,01 \%$ de lisina e de $0,015 \%$ de metionina + cistina presentes na matriz nutricional da enzima de acordo com a Syngenta Seeds Ltda.

As características de desempenho avaliadas foram: consumo de ração, produção de ovos (\%/ave/dia), peso dos 
Tabela 1 - Composição das dietas experimentais

\begin{tabular}{lcc}
\hline & Controle positivo & Controle negativo \\
\hline Milho & 62,372 & 64.607 \\
Farelo de soja (45\%) & 23,675 & 23,273 \\
Óleo & 2,806 & 1,587 \\
Fosfato bicálcico & 1,343 & 0,295 \\
Calcário & 8,894 & 9,262 \\
Sal comum & 0,483 & 0,482 \\
DL-metionina (99\%) & 0,209 & 0,191 \\
L-lisina (78,5\%) & 0,008 & 0,002 \\
Premix vitamínico & 0,100 & 0,100 \\
Premix mineral & 0,050 & 0,050 \\
Cloreto de colina (60\%) & 0,050 & 0,050 \\
Antioxidante & 0,010 & 0,010 \\
Amido4 & - & 0,100 \\
\hline Composição nutricional calculada & \\
\hline Energia metabolizável & $2.900(2900)^{5}$ & $2.855(2855)^{5}$ \\
(kcal/kg) & & $15,98(15,64)$ \\
Proteína bruta (\%) & $16,00(16,00)$ & $3,705(3,705)$ \\
Cálcio (\%) & $3,820(3,820)$ & $0,150(0,150)$ \\
Fósforo disponível (\%) & $0,341(0,341)$ & $0,731(0,731)$ \\
Lisina digestível (\%) & $0,741(0,741)$ & $0,659(0,659)$ \\
Met + Cis digestível (\%) & $0,674(0,674)$ & $0,426(0,371)$ \\
Metionina digestível (\%) & $0,443(0,371)$ & $0,540(0,459)$ \\
Treonina digestível (\%) & $0,540(0,489)$ & $0,170(0,170)$ \\
Triptofano digestível (\%) & $0,170(0,170)$ & $0,977(0,741)$ \\
Arginina digestível (\%) & $0,982(0,741)$ & $0,615(0,615)$ \\
Isoleucina digestível (\%) & $0,617(0,615)$ & $0,675(0,667)$ \\
Valina digestível (\%) & $0,675(0,667)$ & \\
\hline 1Prenix vita & & \\
\hline
\end{tabular}

${ }^{1}$ Premix vitamínico (quantidade por kg de ração): vitamina A - 10.000 UI; vitamina $\mathrm{D}_{3}-2.000 \mathrm{UI}$; vitamina $\mathrm{E}-35 \mathrm{UI}$; vitamina $\mathrm{K}_{3}-1,7 \mathrm{mg}$; vitamina $\mathrm{B}_{6}$ - 2,4 mg; vitamina $\mathrm{B}_{12}$ - $12 \mathrm{mg}$; ácido pantotênico - 12,0 mg; biotina - 0,07 mg; ácido nicotínico - $35 \mathrm{~g}$.

2 Premix mineral (quantidade por kg de ração): Mn - 65 mg; Fe - 50,0 mg; Zn 60,0 mg; Cu - 10,0 mg; I - 0,8 mg; Se - 0,3 mg.

${ }^{3}$ Butil hidroxi tolueno $99 \%$

${ }^{4}$ Fitase (80,160 e $\left.240 \mathrm{~g} / \mathrm{t}\right)$ substitui o amido nestas quantidades nas dietas 3, 4 e 5 , respectivamente.

${ }^{5}$ Exigência mínima para calcular as dietas experimentais por intermédio de programação linear.

ovos, massa de ovos (g/ave/dia), conversão alimentar por massa de ovos e conversão alimentar por dúzia de ovos.

Para obtenção dos componentes do ovo, foram avaliados os pesos de gema, albúmen e casca utilizando-se seis ovos de cada repetição, coletados aleatória e diariamente do total de ovos coletados nos três últimos dias de cada período. Os ovos de cada repetição e de cada dia foram pesados individualmente em balança com precisão de $0,001 \mathrm{~g}$ e, depois de pesados, foram identificados e quebrados. A gema de cada ovo foi pesada e a respectiva casca foi lavada e seca ao ar para posterior obtenção do peso da casca sem a membrana interna. O peso do albúmen foi calculado como a diferença entre o peso do ovo e os pesos da gema e da casca.

No ensaio de metabolismo (experimento 2) utilizaram-se, simultaneamente, as 360 poedeiras com 32 semanas de idade do experimento 1 , portanto, manteve-se o mesmo delineamento adotado no experimento de desempenho.
As dietas fornecidas foram pesadas no início e no final do período total de coleta com a finalidade de se obter o consumo médio de ração e a energia bruta consumida em cada tratamento. Sob as gaiolas foram colocadas bandejas metálicas, revestidas com plásticos, para permitir a coleta das excretas, que foi feita diariamente, em intervalos de 8 horas, durante cinco dias.

A quantidade de ração consumida e a produção de excretas no período foram quantificadas e, do total de excretas produzidas, uma alíquota de $400 \mathrm{~g}$ foi seca em estufa de ventilação forçada por 72 horas. Posteriormente, as amostras foram moídas e encaminhadas ao laboratório, juntamente com amostras das rações, para determinação dos teores de matéria seca, do nitrogênio e do fósforo de acordo com metodologia descrita por Silva (1990).

Todas as análises foram realizadas em duplicatas no Laboratório de Nutrição Animal do Departamento de Zootecnia da UFV. Os valores de energia bruta (EB) foram determinados por meio de uma bomba calorimétrica adiabática.

Após a obtenção dos resultados das análises laboratoriais das dietas e das excretas, foram calculados os valores do coeficiente de digestibilidade aparente da matéria seca (CDAMS), da energia metabolizável aparente (EMA) e da energia metabolizável corrigida (EMAn), bem como seus respectivos coeficientes de metabolizabilidade (CMEM e CMEMn); além do balanço de nitrogênio (BN). $O$ coeficiente de metabolizabilidade indica a porcentagem de EB metabolizada na forma de EMA e EMAn, calculada utilizando-se os valores de EM divididos pela EB referente a cada tratamento. Determinaram-se também os valores médios de ingestão, de excreção e de retenção aparente para o fósforo e para o cálcio.

As avaliações estatísticas de ambos os experimentos foram feitas utilizando análise de variância (Anova) e com comparação de médias pelo teste de Student-NewmanKeul (SNK), a 5\% de probabilidade, utilizando o software SAEG(UFV, 2000).

\section{Resultados e Discussão}

A adição da enzima Quantum ${ }^{T M}$ Fitase não alterou ( $\mathrm{P}>0,05)$ o desempenho médio das aves, avaliado pelo consumo de ração, pela produção de ovos e pelo peso dos ovos (Tabela 2). No entanto, Borrmann (1999) observou maior consumo de ração em aves alimentadas com ração com baixo nível de fósforo disponível (0,18\%) e com fitase em relação a aves alimentadas com ração controle $(0,36 \% \mathrm{Pd}$ e sem adição de fitase). 
Tabela 2 - Desempenho de poedeiras alimentadas com rações suplementadas com fitase no período de 24 a 36 semanas de idade

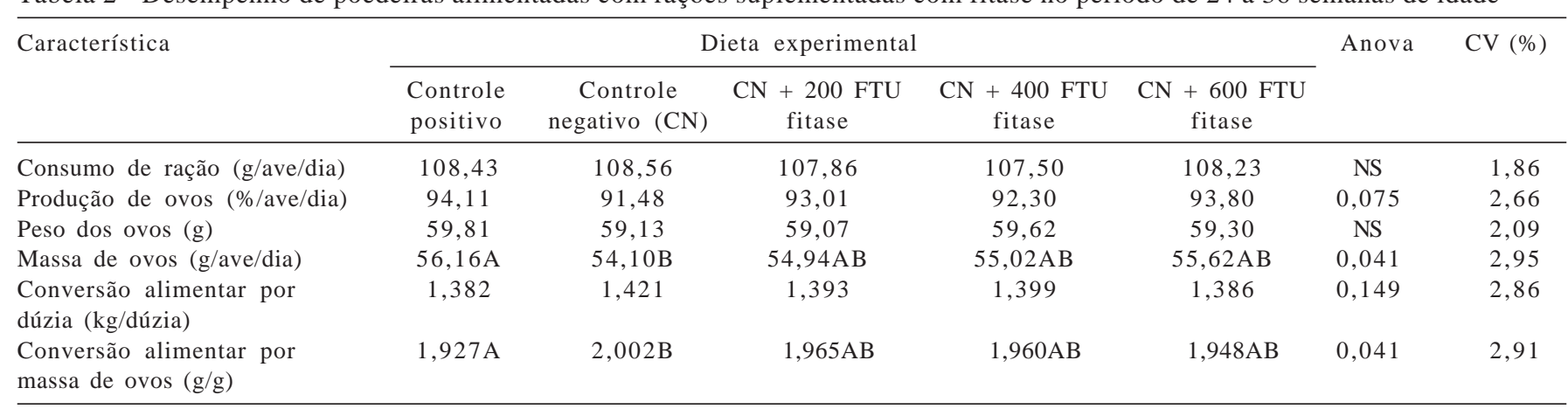

Médias seguidas de letras distintas na mesma linha diferem entre si $(\mathrm{P}<0,05)$ pelo teste SNK.

De forma similar, Ligeiro (2007) encontrou consumo de ração superior para aves que receberam dieta com fitase em relação a aves que receberam dieta sem fitase (0 FTU de fitase/kg de ração), correspondendo a um consumo médio de 101,66 e 99,22 g/ave/dia, respectivamente.

Esses resultados corroboram com os de Ceylan et al. (2003), que também não observaram efeito positivo sobre a produção de ovos em poedeiras de 20 a 40 semanas de idade alimentadas com rações com baixo nível de fósforo disponível (0,20\%) e suplementadas com 300 FTU de fitase/ kg de ração.

Da mesma forma, Bess et al. (2006) não constataram diferenças significativas na porcentagem de postura em matrizes de corte alimentadas com dietas com valorização plena da matriz nutricional da fitase, ou seja, com níveis nutricionais reduzidos em comparação às aves que receberam dieta com níveis nutricionais adequados e sem fitase.

Avaliando poedeiras da $20^{\underline{a}}$ a $60^{\underline{a}}$ semana de idade, Boling et al. (2000) também não observaram diferenças significativas para a porcentagem de postura entre as aves alimentadas com dieta contendo $0,10 \%$ Pd e 300 FTU de fitase/kg de ração e aquelas mantidas com dieta contendo 0,45\% Pd e sem suplementação de fitase.

No entanto, Francesch et al. (2005) observaram melhor porcentagem de postura em poedeiras alimentadas com rações à base de milho contendo $0,11 \%$ de Pd e suplementadas com fitase (150, 300 e 450 FTU de fitase/kg de ração) em comparação a aves alimentadas com 0,32\% de Pd.

Carlos \& Edwards (1998) também não verificaram efeito significativo no peso dos ovos de poedeiras alimentadas com dietas à base de milho e farelo de soja, contendo $0,10 \%$ de Pd e 600 FTU de fitase/kg de ração, no período da 24a a 32 a semana de idade.

Por outro lado, Gordon \& Roland (1997) observaram diminuição no peso dos ovos das aves que consumiram dietas com $0,10 \%$ Pd e isentas de fitase; porém, quando adicionada fitase (300 FTU/kg de ração), esse efeito adverso foi corrigido.

Poedeiras mantidas com a dieta controle positivo apresentaram melhores valores para massa de ovo e conversão alimentar por massa de ovo em comparação àquelas que receberam dietas controle negativo. No entanto, com a adição da enzima fitase, os valores de massa de ovos e da conversão alimentar por massa de ovos foram semelhantes $(\mathrm{P}>0,05)$ aos encontrados na dieta do controle positivo. Não foi observado efeito significativo $(\mathrm{P}>0,05)$ para a conversão alimentar por dúzia (Tabela 3).

Entretanto, Jalal \& Scheideler (2001) verificaram aumento na $\mathrm{MO}$ e na CAMO de poedeiras mantidas com dietas com nível reduzido de fósforo $(0,10 \%$ Pd) e suplementadas com fitase (250 e 300 FTU de fitase/kg de ração) em relação àquelas que receberam a dieta controle $(0,45 \% \mathrm{Pd})$.

Tabela 3 - Características do ovo de poedeiras alimentadas com rações suplementadas com fitase no período de 24 a 36 semanas de idade

\begin{tabular}{|c|c|c|c|c|c|c|c|}
\hline \multirow[t]{2}{*}{ Característica } & \multicolumn{5}{|c|}{ Dieta experimental } & \multirow[t]{2}{*}{ Anova } & \multirow[t]{2}{*}{ CV (\%) } \\
\hline & $\begin{array}{l}\text { Controle } \\
\text { positivo }\end{array}$ & $\begin{array}{c}\text { Controle } \\
\text { negativo }(\mathrm{CN})\end{array}$ & $\begin{array}{c}\mathrm{CN}+200 \mathrm{FTU} \\
\text { fitase }\end{array}$ & $\begin{array}{c}\mathrm{CN}+400 \mathrm{FTU} \\
\text { fitase }\end{array}$ & $\begin{array}{c}\mathrm{CN}+600 \mathrm{FTU} \\
\text { fitase }\end{array}$ & & \\
\hline Peso da gema (g) & 14,51 & 14,66 & 14,50 & 14,60 & 14,71 & NS & 2,82 \\
\hline Peso da casca (g) & $5,46 \mathrm{AB}$ & $5,31 \mathrm{~B}$ & $5,45 \mathrm{AB}$ & $5,55 \mathrm{~A}$ & $5,52 \mathrm{~A}$ & 0,026 & 3,38 \\
\hline Peso do albúmen (g) & 39,47 & 39,24 & 39,59 & 40,27 & 39,58 & NS & 3,59 \\
\hline Gema (\%) & 24,42 & 24,79 & 24,36 & 24,17 & 24,61 & NS & 3,50 \\
\hline Casca (\%) & 9,19 & 8,96 & 9,15 & 9,19 & 9,24 & 0,274 & 3,48 \\
\hline Albúmen (\%) & 66,39 & 66,25 & 66,49 & 66,64 & 66,15 & NS & 1,51 \\
\hline
\end{tabular}

Médias seguidas de letras distintas na mesma linha diferem entre si $(\mathrm{P}<0,05)$ pelo teste SNK. 
Portanto, não foram observadas diferenças significativas entre os parâmetros avaliados, o que indica que a matriz nutricional preconizada para fitase atendeu plenamente as exigências das aves, mesmo quando utilizadas dietas com níveis nutricionais reduzidos.

O mesmo foi observado por Fernandes et al. (2003) e Shelton et al. (2004) em experimentos com frangos de corte. Esses autores, ao utilizarem a matriz nutricional da fitase recomendada pelo fabricante, verificaram que a redução dos níveis nutricionais adotados em dietas com fitase, proporcionou resultados de desempenho semelhantes aos do tratamento controle, composto por níveis nutricionais adequados e sem inclusão de fitase.

Com exceção do peso da casca, não houve diferença significativa $(\mathrm{P}>0,05)$ entre os demais componentes do ovo (Tabela 4). A suplementação de fitase na dieta controle negativo proporcionou aumento no peso de casca, no entanto, não houve diferença estatística $(P>0,05)$ em relação às poedeiras mantidas com a dieta controle positivo. As aves alimentadas com a ração controle negativo sem suplementação da enzima (controle negativo) apresentaram numericamente menor peso de casca, mas não diferiram das poedeiras alimentadas com a ração controle positivo.

Trabalhando com poedeiras da $21^{\underline{a}}$ a $41^{\underline{a}}$ semanas de idade, Lim et al. (2003) verificaram que a suplementação de 300 FTU de fitase/kg de ração determinou melhora na qualidade externa dos ovos, em virtude da redução do número de ovos quebrados e com casca mole (Tabela 3).

Poedeiras alimentadas com a dieta controle apresentaram maiores valores de EMA (88 kcal/kg MS) e EMAn (77 kcal/kg MS) em comparação àquelas que receberam dietas controle negativo (Tabela 4). No entanto, a suplementação de 600 FTU de fitase proporcionou resultados de EMAn semelhantes $(\mathrm{P}>0,05)$ aos encontrados no controle positivo.

No entanto, Lan et al. (2002) avaliaram os valores de EM em dietas à base de milho e farelo de soja e observaram que a adição da fitase (250 e 500 FTU/kg de ração) em dietas com baixo nível de fósforo disponível proporcionou valores de EMA superiores aos encontrados em uma dieta controle.

Ravindran et al. (2000) mostraram que a fitase promove aumento na utilização de energia, independentemente dos efeitos sobre a digestão de aminoácidos. Isso ocorre pelo fato de que, no trato digestório, os minerais complexados com o ácido fítico formam, juntamente com os lipídeos, reações de saponificação, prejudicando a utilização de lipídeos. A enzima fitase neste caso age liberando o complexo fitato-mineral e impedindo a formação desses sabões metálicos, o que possibilita melhor utilização da energia derivada dos lipídeos.

As aves submetidas aos tratamentos 4 e 5 apresentaram maiores coeficientes de digestibilidade aparente da matéria seca, diferindo estatisticamente dos demais tratamentos. Esses resultados refletem o efeito benéfico da enzima fitase sobre a hidrólise do ácido fítico, liberando nutrientes e enzimas endógenas complexadas e aumentando a digestibilidade dos nutrientes nas dietas para poedeiras. Aumento no coeficiente de digestibilidade aparente da matéria seca, semelhantes ao verificado neste ensaio também foram observados por Yi et al. (1996a) em ensaios de digestibilidade aparente com frangos de corte e com perus.

Neste experimento, o coeficiente de variação (CV\%) apresentou baixos valores, o que é normal em ensaios de metabolismo, demonstrando que as médias não variaram muito em torno da média geral de digestibilidade da matéria seca.

Poedeiras alimentadas com a dieta do controle positivo apresentaram maior balanço de nitrogênio em relação àquelas mantidas com as dietas do controle negativo (Tabela 5). A retenção de nitrogênio em poedeiras não foi afetada pelo nível dietético de fitase. A adição da enzima fitase proporcionou aumento nos coeficientes de metabolizabilidade da EM e da EMn semelhante $(\mathrm{P}>0,05)$ aos valores encontrados para poedeiras mantidas com a dieta do controle positivo.

Tabela 4 - Consumo de matéria seca (CMS), coeficiente de digestibilidade aparente da matéria seca (CDAMS), energia metabolizável aparente (EMA) e energia metabolizável aparente corrigida (EMAn) das dietas experimentais

\begin{tabular}{|c|c|c|c|c|}
\hline \multirow[t]{2}{*}{ Dieta experimental } & \multirow[t]{2}{*}{ CMS (g) } & \multirow[t]{2}{*}{ CDAMS (\%) } & \multicolumn{2}{|c|}{ EMA (kcal/kg) } \\
\hline & & & EMA (MS) & EMAn (MS) \\
\hline Controle positivo & 2.919 & $73,46 \mathrm{~B}$ & $3.432 \mathrm{~A}$ & $3.320 \mathrm{~A}$ \\
\hline Controle negativo (CN) & 2.916 & $73,76 \mathrm{~B}$ & $3.344 \mathrm{~B}$ & $3.243 C$ \\
\hline CN +200 FTU fitase & 3.026 & $73,49 B$ & 3.353B & $3.255 \mathrm{BC}$ \\
\hline $\mathrm{CN}+400$ FTU fitase & 2.996 & $74,71 \mathrm{~A}$ & $3.381 \mathrm{~B}$ & $3.278 \mathrm{BC}$ \\
\hline $\mathrm{CN}+600$ FTU fitase & 3.002 & $74,78 \mathrm{~A}$ & 3.389B & $3.290 \mathrm{AB}$ \\
\hline Anova & 0,055 & 0,002 & 0,000 & 0,000 \\
\hline CV (\%) & 3,75 & 1,39 & 1,23 & 1,17 \\
\hline
\end{tabular}

Médias seguidas de letras distintas na mesma coluna diferem entre si $(\mathrm{P}<0,05)$ pelo teste SNK. 
Tabela 5 - Coeficiente de metabolizabilidade da energia metabolizável(CMEM), coeficiente de metabolizabilidade da energia metabolizável corrigida (CMEMn) e balanço de nitrogênio (BN) das dietas experimentais

\begin{tabular}{lccc}
\hline Dieta experimental & CMEM (\%) & CMEMn (\%) & BN (g N retido/ave/dia) \\
\hline Controle positivo & 81,02 & $78,38 \mathrm{AB}$ & $1,341 \mathrm{~A}$ \\
Controle negativo (CN) & 80,27 & $77,86 \mathrm{~B}$ & $1,205 \mathrm{~B}$ \\
CN + 200 FTU fitase & 80,48 & $78,13 \mathrm{AB}$ & $1,204 \mathrm{~B}$ \\
CN + 400 FTU fitase & 81,17 & $78,70 \mathrm{AB}$ & $1,252 \mathrm{~B}$ \\
CN + 600 FTU fitase & 81,35 & $78,97 \mathrm{~A}$ & $1,208 \mathrm{~B}$ \\
Anova & 0,049 & 0,038 & 0,002 \\
CV $\%)$ & 1,23 & 1,17 & 7,56 \\
\hline
\end{tabular}

Médias seguidas de letras distintas na mesma coluna diferem entre si $(\mathrm{P}<0,05)$ pelo teste SNK.

Poedeiras alimentadas com a dieta controle positivo apresentaram maiores ingestão, excreção e retenção de fósforo (Tabela 6). Em comparação às dietas controle negativo, a adição de fitase mostrou tendência numérica para aumentar a retenção de fósforo e cálcio. O controle positivo apresentou o maior valor de fósforo excretado, que pode ser explicado pela maior quantidade de fósforo na dieta.

A concentração de fósforo excretado decresceu aproximadamente $35,9 \%$ em poedeiras alimentadas com rações contendo $0,15 \%$ Pd e 600 FTU de fitase/kg de ração em comparação àquelas que consumiram a dieta com 0,34\% Pd e sem suplementação de fitase. Este fato se deve, principalmente, à diminuição de $78 \%$ na quantidade de fosfato bicálcico na formulação das dietas quando valorizada a matriz da enzima, ou seja, a quantidade de fósforo fítico que a fitase teoricamente disponibilizaria dos ingredientes de origem vegetal aos animais.

Estes resultados corroboram os de Boling et al. (2000), que também observaram decréscimo na excreção de fósforo em poedeiras alimentadas com dietas contendo $0,10 \% \mathrm{Pd}$ e 300 FTU de fitase/kg de ração em comparação àquelas que consumiram dietas com $0,45 \%$ Pd e sem suplementação de fitase.

Observando o parâmetro cálcio retido (mg/ave/dia) e o percentual de cálcio retido (\%), verificou-se que a dieta controle negativo foi a que apresentou os menores valores de cálcio retido $(\mathrm{P}<0,05)$.

A suplementação de fitase ao controle negativo foi suficiente para melhorar $(P<0,05)$ os valores de excreção, retenção (mg/ave/dia) e retenção de cálcio (\%), não diferindo, portanto, do controle positivo.

A dieta controle promoveu valores de cálcio excretado e retido ( $\mathrm{mg} / \mathrm{ave} / \mathrm{dia})$ similares $(\mathrm{P}>0,05)$ aos obtidos com as dietas suplementadas com fitase; entretanto, as aves alimentadas com a ração controle apresentaram maior percentual de retenção de cálcio $(\mathrm{P}<0,01)$ em comparação àquelas que receberam as dietas suplementadas com fitase.

As aves que receberam dietas com níveis nutricionais reduzidos e suplementadas com fitase ingeriram menor quantidade de cálcio em relação àquelas que receberam a dieta com nível nutricional normal e sem fitase.

Tabela 6 - Balanço de fósforo e cálcio das dietas experimentais suplementadas com fitase

\begin{tabular}{|c|c|c|c|c|c|c|c|}
\hline & \multicolumn{5}{|c|}{ Dieta experimental } & Anova & CV (\%) \\
\hline \multicolumn{8}{|c|}{ Fósforo } \\
\hline Ingerido(mg/ave/dia) & $589 \mathrm{~A}$ & $385 B$ & $390 \mathrm{~B}$ & $387 \mathrm{~B}$ & 389B & 0,0001 & 2,13 \\
\hline Excretado (mg/ave/dia) & $389 \mathrm{~A}$ & $253 B$ & $255 B$ & $253 B$ & 249B & 0,0001 & 3,53 \\
\hline \multicolumn{8}{|c|}{ Cálcio } \\
\hline Ingerido(mg/ave/dia) & $5,62 \mathrm{~A}$ & $5,16 \mathrm{~B}$ & $5,25 B$ & $5,21 \mathrm{~B}$ & $5,21 \mathrm{~B}$ & 0,0001 & 2,97 \\
\hline Excretado (mg/ave/dia) & $2,56 \mathrm{~B}$ & $2,72 \mathrm{~A}$ & $2,54 \mathrm{~B}$ & $2,64 \mathrm{AB}$ & $2,55 \mathrm{~B}$ & 0,0103 & 5,21 \\
\hline Retido (mg/ave/dia) & $3,06 \mathrm{~A}$ & $2,44 \mathrm{C}$ & $2,71 \mathrm{~A}$ & $2,57 \mathrm{AC}$ & $2,66 \mathrm{~A}$ & 0,0001 & 6,15 \\
\hline Retido (\%) & $54,46 \mathrm{~A}$ & $47,24 \mathrm{C}$ & $51,56 \mathrm{~B}$ & $49,29 B$ & $51,12 \mathrm{~B}$ & 0,0001 & 4,87 \\
\hline
\end{tabular}

Médias seguidas de letras distintas na mesma linha diferem $(\mathrm{P}<0,05)$ entre si pelo teste SNK. 


\section{Conclusões}

A matriz nutricional preconizada para fitase permite $o$ atendimento pleno das exigências das aves, garantindo o desempenho de poedeiras. Os componentes do ovo não são influenciados pelos tratamentos, com exceção do peso da casca, que aumenta com a suplementação de fitase nas dietas. A adição de 600 FTU de fitase em dietas à base de milho e farelo de soja proporciona melhoria no metabolismo dos nutrientes em dietas nutricionalmente deficientes.

\section{Literatura Citada}

BESS, F.; ROSA, A.P.; KRABBE, E.L. et al. Efeito da adição de fitase sobre a percentagem de postura e densidade de ovos em matrizes de corte. Revista Brasileira de Ciência Avícola, supl.8, p.106, 2006.

BOLING, S.D.; DOUGLAS, M.W.; SHIRLEY, R.B. et al. The effects of various dietary levels of phytase and avaible phosphorus on performance of laying hens. Poultry Science, v.79, n.3-4, p.535-538, 2000.

BORRMANN, M.S.L. Efeitos da adição de fitase, com diferentes níveis de fósforo disponível, em rações de poedeiras de segundo ciclo. 1999. 74f. Dissertação (Mestrado em Zootecnia) - Universidade Federal de Lavras, Lavras, 1999.

CARLOS, A.B.; EDWARDS, H.M. The effects of 1,25dihydroxycholecalciferol and phytase on the natural phytate phosphorus utilization by laying hens. Poultry Science, v.77, n.6, p.850-858, 1998.

CEYLAN, N.; SCHEIDELER, S.E.; STILBORN, H.L. High available phosphorus corn and phytase in layer diets. Poultry Science, v.82, p.789-795, 2003.

CROMWELL, G.L.; COFFEY, R.D. Phosphorus - A key essential nutrient, yet a possible major polluant - its central role in animal nutrition. In: ALLTECH'S ANNUAL SYMPOSIUM OF BIOTECHNOOGY IN THE FEED INDUSTRY, 7., 1991, Nicholasville. Proceedings... Nicholasville: Alltech Technical Publications, 1991. p.133-145.

CROMWELL, G.L.; COFFEY, R.D.; PARKER, G.R. Efficacy of a recombinant-derived phytase in improving the bioavailability of phosphorus in corn-soybean meal diets for pigs. Journal of Animal Science, v.73, n.7, p.2000-2008, 1995.

FERNANDES, E.A.; HONSI BRANDEBURGO, M.I.; SILVEIRA, M.M. et al. Avaliação da adição de fitase em dietas de frangos de corte. Revista Brasileira de Ciência Avícola, supl. 5, p.33, 2003.

FRANCESCH, M.; BROZ, J.; BRUFAU, J. Effects of an experimental phytase on performance, egg quality, tibia ash content and phosphorus bioavailability in laying hens fed on maize- or barley-based diets. British Poultry Science, v.46, n.3, p.340348, 2005.

GORDON, R.W.; ROLAND, D.A. Performance of commercial laying hens fed various phosphorus levels, with and without supplemental phytase. Poultry Science, v.76, n.8, p.1172-1177, 1997.
JALAL, M.A.; SHEIDELER, S.E. Effect of supplementation of two different sources of phytase on egg production parameters in laying hens and nutrient digestibility. Poultry Science, v.80, n.9-10, p.1463-1471, 2001.

LAN, G.Q.; ABDULLAH, N.; JALALUDIN, S. et al. Efficacy of supplementation of a phytase-producing bacterial culture on the performance and nutrient use of broiler chickens fed corn-soybean meal diets. Poultry Science, v.81, n.10, p.1522-1532, 2002.

IIGEIRO, E.C. Efeito da utilização da fitase sobre o desempenho, qualidade dos ovos, avaliação econômica e excreção de fósforo e nitrogênio de poedeiras comerciais alimentadas com rações contendo ingredientes alternativos. 2007. 81f. Dissertação (Mestrado em Zootecnia) - Universidade Estadual Paulista, Faculdade de Ciências Agrárias e Veterinárias, Jaboticabal, 2007.

LIM, H.S.; NAMKUNG, H.; PAIK, I.K. Effects of phytase supplementation on the performance, egg quality, and phosphorous excretion of laying hens fed different levels of dietary calcium and nonphytate phosphorous. Poultry Science, v.82, n.1-2, p.92-99, 2003.

MOREIRA, J.A.; VITTI, D.M.S.S.; LOPES, J.B. Estudo dos efeitos da enzima fitase em rações para suínos através do radiofósforo - P-32. In: REUNIÃO ANUAL DA SOCIEDADE BRASILEIRA DE ZOOTECNIA, 37., 2000, Viçosa, MG. Anais... Viçosa, MG: Sociedade Brasileira de Zootecnia, 2000. p.292.

MOREIRA, J.A.; VITTI, D.M.S.S.; TRINDADE NETO, M.A. et al. J.B. Enzima fitase e farelo de arroz desengordurado para suínos. In: REUNIÃO ANUAL DA SOCIEDADE BRASILEIRA DE ZOOTECNIA, 38., Piracicaba, 2001. Anais..., Piracicaba: Sociedade Brasileira de Zootecnia, 2001. p.703-704.

NELSON, T.S.; SHIEH, T.R.; WODZINSKI, R.J. et al. The availability of phytate phosphorus in soybean meal before and after treatment with mold phytase. Poultry Science, v.47, p.1842-1848, 1968.

RAVINDRAN, V.; CABAHUG, S.; RAVINDRAN, G. et al. Response of broiler chickens to microbial phytase supplementation as influenced by dietary phytic acid and non-phytate phosphorous levels. II. Effects on apparent metabolizable energy, nutrient digestibility and nutrient retention. British Poultry Science, v.41, p.193-200, 2000.

ROSTAGNO, H.S.; ALBINO, L.F.T.; DONZELE, J.L. et al. Tabelas brasileiras para aves e suínos: composição de alimentos e exigências nutricionais. Viçosa, MG: Universidade Federal de Viçosa, 2005. 186p.

UNIVERSIDADE FEDERAL DE VIÇOSA - UFV. SAEG - Sistema de análises estatísticas e genéticas. Versão 8.0. Viçosa, MG: 2000. 59p. (Manual do usuário).

SHELTON, J.L.; SOUTHERN, L.L.; GASTON, L.A. Evaluation of the nutrient matrix values for phytase in broilers. Journal Applied Poultry Research, v.13, n.3, p.213-221, 2004.

SILVA, D.J. Análise de alimentos (métodos químicos e biológicos). Viçosa, MG: Universidade Federal de Viçosa, 1990. 166p.

SIMONS, P.C.M.; VERSTEEGH, H.A.V.; JONGLOED, A.W. et al. Improvement of phosphorus availability by microbial phytase in broilers and pig. British Journal Nutrition, v.64, n.2-3, p.525-540, 1990.

YI, Z.; KORNEGAY, E.T.; DENBOW, D.W. Effect of microbial phytase on nitrogen and amino acid digestibility and nitrogen retention of turkey poutry fed corn-soybean meal diets. Poultry Science, v.75, n.8, p.979-990, 1996a. 